
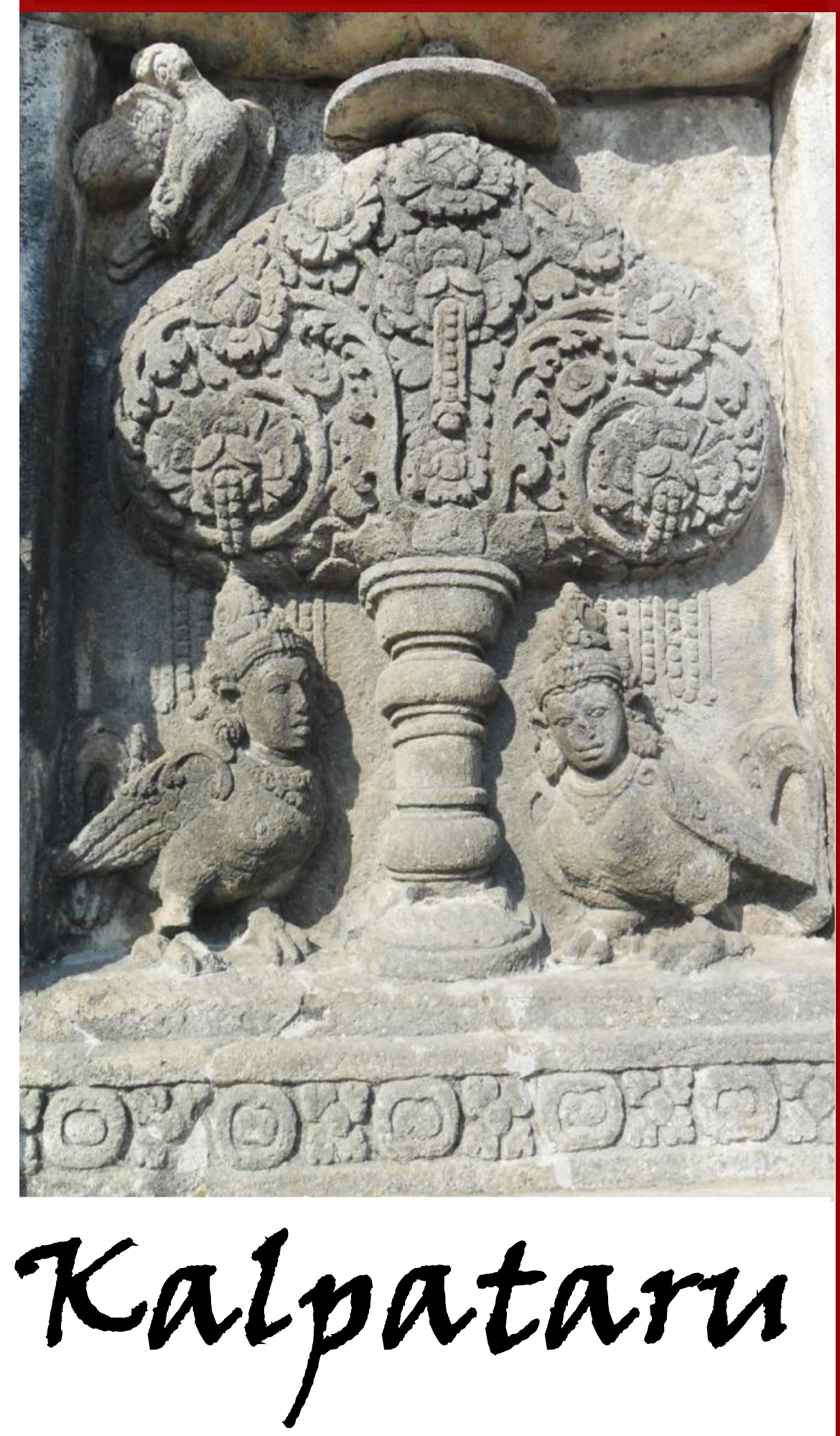

JURNAL SEJARAH DAN PEMBELAJARAN SEJARAH

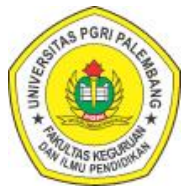

Program Studi Pendidikan Sejarah Jurusan Pendidikan IPS

Fakultas Keguruan dan IImu Pendidikan Universitas Persatuan Guru Republik Indonesia Palembang
Kajian Tata Ruang Lukisan Dinding Pada Batu Balai di Desa Tegur Wangi Lama Kota Pagaralam Sebagai Sumber Pembelajaran Sejarah

Muhammad Randi Saputra, H. Rudi Asri

Nilai Sejarah Toponim di Kecamatan Bukit Kecil Kota Palembang Sebagai Sumber Pembelajaran Sejarah di SMP Negeri 33 Palembang

Dedi Berianto

Upaya Meningkatkan Kualitas Pembelajaran Sejarah Melalui Penerapan Outdoor Learning Berbasis Inkuiri di SMA Muhammadiyah 1 Palembang

Arman, Fatmah

Senjang: Sejarah Tradisi Lisan Masyarakat Musi Banyuasin

Brian Apriadi, Eva Dina Chairunisa

Peningkatan Hasil Belajar dan Aktifitas Siswa Melalui Model Pembelajaran Discovery Learning di SMA Negeri 8 Palembang

Sri Mulyati, Nurhayati Dina, Apriana

Jenis-Jenis Peninggalan Megalit di Desa Tanjung Aro Sebagai Sumber Pembelajaran Sejarah di Kelas X SMA Muhammadiyah 3 Palembang Tahun Ajaran 2017/2018

Lita Sepriani

Persepsi Siswa Terhadap Penggunaan Media Film Dokumenter Materi Kehidupan Manusia Purba Pada Mata Pelajaran Sejarah di SMK Negeri 6 Palembang M. Edo Nuryana

Sejarah Tulung Selapan Sebagai Sumber Penulisan Sejarah Lokal Ogan Komering Ilir

Muhamad Idris

Pengaruh Model Pembelajaran Explicit Instruction Terhadap Hasil Belajar Siswa Pada Mata Pelajaran Sejarah di Sekolah Menengah Atas Negeri 1 Gelumbang Ramoni Handayani

Pengaruh Penggunaan Media Film Dokumenter Terhadap Hasil Belajar Siswa Pada Mata Pelajaran Sejarah di Sekolah Menengah Atas Sriguna Palembang Vina Pratiwi 


\section{Kalpataru}

Jurnal Sejarah dan Pembelajaran Sejarah

Volume 4, Nomor 2, Desember 2018

Penanggung Jawab

Dr. Dessy Wardiah, M.Pd.

Ketua Dewan Redaksi

Drs. Sukardi, M.Pd.

\section{Penyunting Pelaksana}

Muhamad Idris, M.Pd.

Eva Dina Chairunisa, M.Pd.

Jeki Sepriady, S.Pd.

Dr. Tahrun, M.Pd.

Drs. Supriyanto, M.Hum.

Dra. Retno Purwati, M.Hum.

Dr. Nor Huda Ali, M.Ag., M.A.

Budi Agung Sudarman, S.S., M.Pd.

Dr. Purmansyah, M.A.

\section{Penyunting Ahli}

(Universitas PGRI Palembang)

(Universitas Sriwijaya Palembang)

(Balai Arkeologi Sumatera Selatan)

(Masyarakat Sejarawan Indonesia Sumsel)

(Balai Bahasa Provinsi Sumatera Selatan)

(Universitas Muhammadiyah Palembang)

\section{Alamat Redaksi}

Program Studi Pendidikan Sejarah

Jurusan Pendidikan IImu Pengetahuan Sosial

Fakultas Keguruan dan IImu Pendidikan Universitas PGRI Palembang

Telp. 0711-510043

Email: jurnalkalpatarusejarah@gmail.com

Website: https://jurnal.univpgri-palembang.ac.id/index.php/Kalpa 


\section{Kalpataru}

\author{
JURNAL SEJARAH DAN
}

PEMBELAJARAN SEJARAH

Terbit dua kali setahun pada Juli dan Desember

Diterbitkan oleh:

Program Studi Pendidikan Sejarah Jurusan Pendidikan IPS

Fakultas Keguruan dan IImu Pendidikan Universitas PGRI Palembang

\section{Gambar Cover: \\ Pohon Kalpataru \\ Candi Prambanan}

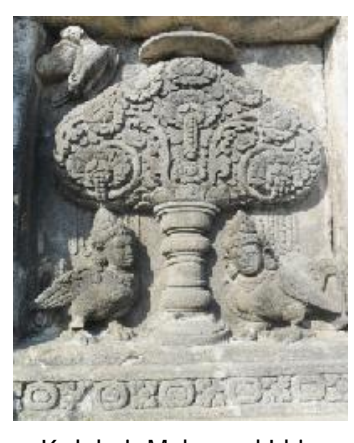

Koleksi: Muhamad Idris

\section{DAFTAR ISI}

Kajian Tata Ruang Lukisan Dinding Pada Batu Balai di Desa Tegur Wangi Lama Kota Pagaralam Sebagai Sumber Pembelajaran Sejarah

Muhammad Randi Saputra, H. Rudi Asri. $.89-98$

Nilai Sejarah Toponim di Kecamatan Bukit Kecil Kota Palembang Sebagai Sumber Pembelajaran Sejarah di SMP Negeri 33 Palembang

Dedi Berianto. 99-110

Upaya Meningkatkan Kualitas Pembelajaran Sejarah Melalui Penerapan Outdoor Learning Berbasis Inkuiri di SMA Muhammadiyah 1 Palembang

Arman, Fatmah.

Senjang: Sejarah Tradisi Lisan Masyarakat Musi Banyuasin

Brian Apriadi, Eva Dina Chairunisa

Peningkatan Hasil Belajar dan Aktifitas Siswa Melalui Model Pembelajaran Discovery Learning di SMA Negeri 8 Palembang

Sri Mulyati, Nurhayati Dina, Apriana.

Jenis-Jenis Peninggalan Megalit di Desa Tanjung Aro

Sebagai Sumber Pembelajaran Sejarah di Kelas X SMA

Muhammadiyah 3 Palembang Tahun Ajaran 2017/2018

Lita Sepriani..

Persepsi Siswa Terhadap Penggunaan Media Film Dokumenter Materi Kehidupan Manusia Purba Pada Mata Pelajaran Sejarah di SMK Negeri 6 Palembang M. Edo Nuryana.

Sejarah Tulung Selapan Sebagai Sumber Penulisan Sejarah Lokal Ogan Komering Ilir Muhamad Idris. $146-153$

Pengaruh Model Pembelajaran Explicit Instruction Terhadap Hasil Belajar Siswa Pada Mata Pelajaran Sejarah di Sekolah Menengah Atas Negeri 1 Gelumbang

Ramoni Handayani. 154-161

Pengaruh Penggunaan Media Film Dokumenter Terhadap Hasil Belajar Siswa Pada Mata Pelajaran Sejarah di Sekolah Menengah Atas Sriguna Palembang

Vina Pratiwi. $162-169$ 


\title{
UPAYA MENINGKATKAN KUALITAS PEMBELAJARAN SEJARAH MELALUI PENERAPAN OUTDOOR LEARNING BERBASIS INKUIRI DI SMA MUHAMMADIYAH 1 PALEMBANG
}

\author{
Arman \\ SMA Muhammadiyah 1 Palembang \\ Email: antif259@gmail.com \\ Fatmah \\ Dosen FKIP Universitas Muhammadiyah Palembang \\ Email: fatmahadfkip@gmail.com
}

\begin{abstract}
ABSTRAK
Tujuan dari penelitian ini adalah untuk mendeskripsikan bagaimana meningkatkan kualitas pembelajaran sejarah melalui pembelajaran Outdoor Learning berbasis Inkuiri di SMA Muhammadiyah 1 Palembang. Penelitian ini dilaksanakan dalam dua siklus, tiap siklus terdiri dari beberapa tahapan yakni perencanaan, tindakan, observasi, refleksi, dan rencana perbaikan. Siklus I dilaksanakan dalam dua kali pertemuan dengan materi Negara Tradisional Hindhu dan Budha. Siklus II dilaksanakan dalam tiga kali pertemuan dengan materi Perkembangan agama Islam di Indonesia. Subjek dari penelitian ini adalah siswa kelas XI IPS OL, dengan jumlah siswa 32. Teknik pengumpulan data yang digunakan meliputi dokumentasi, observasi, wawancara, dan tes. Hasil penelitian menunjukkan bahwa keaktifan dan hasil belajar siswa mengalami peningkatan dari pra siklus hingga siklus II. Proses (keaktifan) dan hasil belajar yang baik ini menunjukkan bahwa kualitas pembelajaran sejarah di kelas XI IPS OL meningkat. Meningkatnya kualitas pembelajaran di kelas XI IPS OL menunjukkan bahwa penerapan Outdoor Learning berbasis Inkuiri berhasil menyelesaikan masalah yang dihadapi.
\end{abstract}

Kata Kunci: Outdoor Learning, Inkuiri, Pembelajaran Sejarah.

\section{A. PENDAHULUAN}

Pembelajaran sejarah pada jenjang Sekolah Menengah Atas (SMA) memerlukan sebuah inovasi dalam pemberian tindakan untuk mengatasi permasalahan yang terjadi didalam kelas. Contoh permasalahan yang dihadapi seperti sumber belajar, model, metode, siswa, dan kemampuan guru dalam menyampaikan materi kepada siswa. Permasalahan-permasalahan tersebut juga terjadi di SMA Muhammadiyah 1 Palembang yang terletak di kecamatan Ario Kemuning kota Palembang. Sejarah merupakan salah satu mata pelajaran yang dalam kegiatan pembelajarannya terdapat permasalahan. Di SMA Muhammadiyah 1 Palembang terdapat beberapa guru pengajar mata pelajaran sejarah, yakni Bapak Asril Sairi, Bapak Kemas Ikmal, Ibu Eka Susilawati dan Ibu Shinta. Alasan mengapa di sekolah ini terdapat lima guru pengajar karena jam pelajaran yang cukup banyak sesuai dengan Kurikulum 2013.

Pada observasi awal, peneliti mendapatkan informasi bahwa terdapat salah satu kelas yang bermasalah dalam proses dan hasil belajar, yakni XI IPS OL. Pembelajaran sejarah di kelas XI IPS OL memerlukan sebuah tindakan khusus untuk menyelesaikan masalah yang dihadapi siswa. Permasalahan yang dihadapi adalah proses dan hasil belajar yang kurang maksimal jika dibandingkan dengan kelas lainnya. Siswa di kelas XI IPS OL terlihat jenuh dan cenderung sulit megikuti pembelajaran yang dilakukan. Kejenuhan siswa dalam mengikuti pembelajaran terjadi karena proses pembelajaran yang secara umum lebih banyak dilaksanakan didalam kelas saja. Akibat dari kejenuhan siswa ini adalah pengaruh pada aktivitas siswa di kelas yang cenderung kurang aktif. Siswa 


\section{Kalpataru, Volume 4, Nomor 2, Desember 2018 (111-115)}

kurang aktif dalam bertanya, menjawab/ pemecahan masalah, mengumpulkan informasi dan diskusi.

Di awal pembelajaran terdapat siswa yang berada diluar kelas dengan aktivitas yang tidak berkaitan dengan pembelajaran. Seharusnya siswa sudah berada didalam kelas dan siap mengikuti pembelajaran. Kesiapan diperlukan agar mampu melaksanakan kegiatan (belajar) dengan baik dimana kesiapan tersebut kesiapan fisik, psikis, dan kematangan dalam melakukan sesuatu yang dipengaruhi oleh pengalaman (Suyono, 2011:126). Guru meminta ketua kelas untuk memanggil siswa yang masih berada diluar kelas. Agar segera masuk dan mengikuti pembelajaran. Setelah semua siswa berada didalam kelas, guru melaksanakan pembelajaran seperti biasa dengan mengucapkan salam, menyampaikan tujuan dan kompetensi dasar yang hendak dicapai. Ketika guru menyampaikan gambaran umum materi, siswa mulai terlihat kurang fokus. Terdapat beberapa siswa yang berbicara dengan teman sebangku ataupun didepannya. Aktivitas siswa ini berjalan dengan waktu yang cukup lama sehingga mengganggu pembelajaran. Guru memberikan peringatan halus untuk berhenti melakukan kegiatan diluar konteks pembelajaran sejarah, tetapi peringatan halus yang diberikan tidak memberikan efek jera pada siswa.

Masalah lain ialah ketika terdapat siswa berinisial SF tidur saat guru menyampaikan materi pembelajaran. Guru menghampiri SF dan menyuruhnya untuk membasuh muka agar tidak mengantuk lagi ketika di kelas. Keadaan ini membuat kelas menjadi gaduh karena beberapa siswa mengejek SF yang tertidur di kelas. Setelah guru menyampaikan gambaran umum materi, dan menyuruh siswa untuk membentuk kelompok diskusi. Instruksi dari guru terlihat kurang diperhatikan oleh siswa karena diskusi tidak berjalan dengan baik. Hal ini terjadi karena terdapat beberapa siswa yang tidak mau berdiskusi. Hal ini berkaitan dengan keaktifan siswa dalam berdiskusi, bertanya, menjawab dan mengumpulkan informasi. Peneliti juga melihat bahwa keaktifan siswa selain berdiskusi juga rendah, misalnya ketika guru memberikan pertanyaan.

Peneliti berasumsi bahwa ketika sebuah proses pembelajaran kurang maksimal, maka hasil belajar siswa juga akan kurang maksimal. Di SMA Muhammadiyah 1 Palembang kelas XI IPS OL telah ditentukan Kriteria Ketuntasan Minimal (KKM) untuk mata pelajaran sejarah adalah 78. Rata-rata nilai tugas siswa kelas XI IPS OL hanya 66,1 dan nilai ulangan harian pertama 66,55. Pada ulanganulangan selanjutnya siswa juga mengalami kendala pada hasil belajarnya. Hasil belajar pada Ulangan Akhir Semester Ganjil juga menunjukkan hasil yang kurang maksimal dengan rata-rata 59.

Rendahnya proses belajar (keaktifan) dan hasil belajar di kelas XI IPS OL menunjukkan bahwa kualitas pembelajaran masih cukup rendah. Pembelajaran merupakan hubungan timbal balik antara tujuan, metode, materi dan evaluasi, serta menciptakan kondisi yang kondusif agar terjadi komunikasi belajar mengajar (Rusman, 2012:15). Pada pernyataan ini jelas terlihat bahwa pembelajaran bukan hanya menyampaikan informasi kepada siswa, tetapi juga terdapat hal-hal yang menjadi kaidah yang harus ditaati. Tujuan pembelajaran secara mutlak harus dijelaskan dan ditentukan sebelum melaksanakan pembelajaran. Hamalik dalam Sanjaya (2011:6) menjelaskan bahwa sistem pembelajaran merupakan kombinasi unsur manusiawai, material, fasilitas, perlengkapan dan prosedur yang berinteraksi untuk mencapai suatu tujuan. Pendapat ini jauh lebih kompleks lagi menjelaskan faktor-faktor yang dapat mempengaruhi pembelajaran.

Peneliti memilih inkuiri terbimbing untuk dipadukan dengan outdoor learning karena langkah-langkah pembelajarannya 
yang cukup mudah diikuti oleh siswa XI IPS $\mathrm{OL}$ dan sesuai dengan permasalahan yang dihadapi di lapangan. Langkah-langkah inkuiri terbimbing pada penelitian ini adalah orientasi, merumuskan masalah, merumuskan hipotesis, mengumpulkan data, menguji hipotesis, dan merumuskan kesimpulan (Sanjaya, 2011:202-205).

\section{B. METODE PENELITIAN}

Lokasi penelitian di lakukan di SMA Muhammadiyah 1 Palembang, Jl. Balayudha No. 21A, kecamatan Kemuning, kota Palembang. Adapun secara geografis SMA Muhammadiyah 1 Palembang berada di kawasan penduduk sebelah Barat berbatasan dengan SMA 1 Aisyiah Palembang dan di sebelah Timur, Utara dan Selatan berbatasan dengan kawasan pemukiman penduduk, melihat kondisi ini maka SMA Muhammadiyah 1 Palembang telah memiliki kondisi lingkungan yang baik, sehingga proses pembelajaran bisa berjalan dengan baik dan efesien.

Penelitian ini dilaksanakan di kelas XI IPS OL, SMA Muhammadiyah 1 Palembang pada tahun ajaran 2018-2019. Penelitian ini dilaksanakan dalam dua siklus, tiap siklus terdiri dari beberapa tahapan yakni perencanaan, tindakan, observasi, refleksi, dan rencana perbaikan. Siklus I dilaksanakan dalam dua kali pertemuan dengan materi Negara Tradisional Hindhu dan Budha: dari masuknya agama Hindhu dan Budha sampai ke Hasil Kebudayaan Hindhu dan Budha. Siklus II dilaksanakan dalam tiga kali pertemuan dengan materi Perkembangan agama Islam di Indonesia (Masuk dan berkembangnya Islam di Indonesia). Subjek dari penelitian ini adalah siswa kelas XI IPS OL, dengan jumlah siswa 32. Teknik pengumpulan data yang digunakan meliputi dokumentasi, observasi, wawancara, dan tes.

Penelitian ini berupaya meningkatkan kualitas pembelajaran yang difokuskan pada proses pembelajaran (keaktifan) dan hasil belajar. Indikator keaktifan pada penelitian ini mengadopsi dari pendapat Sudjana (2011:61) dengan beberapa penyesuaian yang menghasilkan empat indikator keaktifan mencakup mengumpulkan informasi, bertanya, menjawab/pemecahan masalah, dan diskusi. Penilaian terhadap hasil belajar dilakukan dengan tes formatif yang dilaksanakan pada akhir siklus. Tujuan penilaian formatif adalah untuk memperbaiki dan menyempurnakan proses pembelajaran agar hasil belajar siswa menjadi baik (Arifin, 2013:35).

Observasi yaitu pengumpulan data dengan cara melihat secara langsung objek yang akan diteliti. Dalam pengumpulan data pada penelitian ini menggunakan teknik observasi langsung dan observasi non partisipatif. Dalam pengumpulan data dilaksanakan dengan observasi langsung karena observer harus berada bersama obyek yang diselidiki untuk melakukan pengamatan dan pencatatan secara langsung di tempat terjadinya peristiwa. Observasi yang dilakukan adalah untuk mengamati secara langsung di lapangan yaitu di Museum Bala Putera Dewa beserta probematika atau kasus yang sedang diteliti terjadi. Teknik ini merupakan pengamatan.

\section{HASIL DAN PEMBAHASAN}

Keaktifan siswa kelas XI IPS OL dalam mengikuti pembelajaran sejarah melalui penerapan outdoor learning berbasis inkuiri. Keaktifan siswa mengalami peningkatan dari pra siklus hingga siklus II (lihat gambar 1). Pada kegiatan pra siklus persentase keaktifan siswa dalam mengumpulkan informasi sebanyak $65.5 \%$, bertanya $57 \%$, menjawab/pemecahan masalah 50.8\%, dan diskusi $65.5 \%$. Pada siklus I persentase keaktifan siswa dalam mengumpulkan informasi sebanyak $78.4 \%$, bertanya $66.3 \%$, menjawab/pemecahan masalah $56.7 \%$, dan diskusi $75 \%$. Pada siklus II persentase keaktifan siswa dalam mengumpulkan informasi sebanyak $81.2 \%$, bertanya $71.5 \%$, menjawab/pemecahan masalah $72.4 \%$, dan diskusi $87 \%$. 


\section{Kalpataru, Volume 4, Nomor 2, Desember 2018 (111-115)}

Persentase keaktifan siswa secara klasikal, meningkat dari $34 \%$ pada pra siklus, menjadi $65 \%$ pada siklus I dan $89 \%$ pada siklus II. Peningkatan keaktifan siswa terjadi karena suasana pembelajaran yang menyenangkan. Siswa juga terlibat aktif dalam kegiatan pembelajaran dengan penerapan outdoor learning berbasis inkuiri.

Kegiatan pembelajaran pada siklus II menjadi lebih menyenangkan karena didesain seperti sebuah objek yang berada di lingkungan sekolah dengan menggunakan running woods yang berasal dari modifikasi running dictation. Running dictation merupakan metode pembelajaran yang melibatkan siswa secara aktif dalam mencari informasi materi pelajaran dengan cara berlari kemudian mendiktekannya kepada anggota kelompoknya (Wati, 2013:18). Siswa menjadi lebih senang dalam mengikuti pembelajaran dibandingkan dengan pra siklus dan siklus I. Bukan hanya rasa senang yang diutamakan oleh peneliti, tetapi sikap aktif siswa dalam mengikuti pembelajaran. Hal ini terbukti bahwa keaktifan siswa semakin meningkat karena suasana belajar yang semakin baik dan siswa semakin aktif karena running woods yang menyenangkan juga merupakan bagian dari inkuiri.

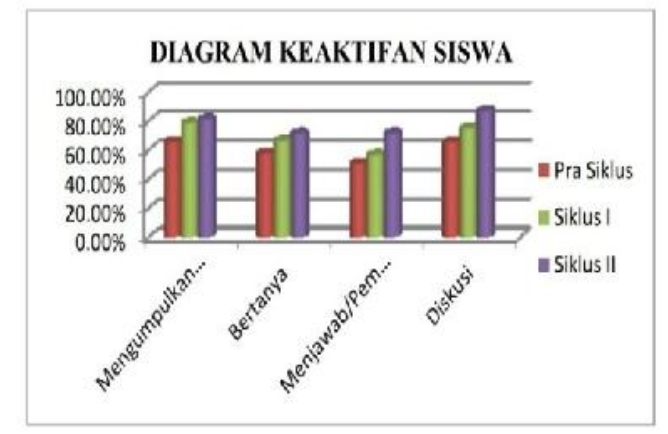

Gambar 1. Keaktifan Siswa (Sumber: Dokumentasi Peneliti)

Terjadinya peningkatan keaktifan siswa dalam mengikuti pembelajaran sesuai dengan pendapat para ahli yang yang mendukung teori konstruktivistik. Piaget dalam Suprihatiningrum (2014) menyatakan sebuah hal penting yang yang perlu dilakukan oleh siswa dalam belajar adalah modifikasi. Makna modifikasi dapat dikatakan sebagai respon yang harus ditampilkan oleh siswa. Kegiatan pembelajaran baik pada siklus I maupun siklus II sebenarnya didesain untuk pembelajaran yang menyenangkan dan santai melalui outdoor learning, tetapi juga dipadukan dengan inkuiri terbimbing (Sanjaya, 2011) yang menuntut siswa aktif mencari dan mengumpulkan informasi untuk menyelesaikan permasalahan. $\mathrm{Hal}$ ini bertujuan untuk memancing siswa dalam memodifikasi stimulus yang diberikan oleh guru pengajar. Upaya ini terlihat cukup berhasil ketika diterapkan di kelas XI IPS OL untuk menyelesaikan permasalahan keaktifan yang dihadapi.

Hasil belajar siswa kelas XI IPS OL dalam mengikuti pembelajaran sejarah melalui penerapan Outdoor Learning berbasis Inkuiri hasil belajar siswa juga mengalami peningkatan dari pra siklus hingga siklus II (lihat gambar 2). Pada pra siklus rata-rata hasil belajar yang diperoleh siswa XI IPS OL adalah 63.5 dan persentase ketuntasan klasikal yang diperoleh adalah 65.8\%. Pada siklus I mengalami peningkatan rata-rata nilai hasil belajar menjadi 67.4 dan persentase ketuntasan klasikal menjadi 69.3\%. Pada siklus II rata-rata nilai hasil belajar 73.4 persentase ketuntasan klasikal hasil belajar siswa, yakni $76.2 \%$. Peningkatan hasil belajar ini tidak lepas dari proses pembelajaran yang semakin baik sehingga memberikan dampak positif terhadap hasil belajar siswa. Hal ini karena proses dan hasil belajar memiliki hubungan yang erat. 


\section{Kalpataru, Volume 4, Nomor 2, Desember 2018 (111-115)}
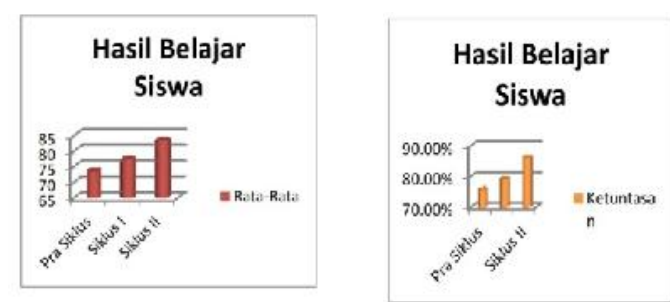

Gambar 2. Hasil Belajar Siswa

(Sumber: Dokumentasi Peneliti)

Peningkatan hasil belajar siswa XI IPS OL menunjukkan sebuah perubahan yang sangat signifikan. Hal ini menunjukkan bahwa penerapan outdoor learning berbasis inkuiri berhasil. Penerapan model ini dapat digunakan sebagai acuan bagi guru jika mengalami masalah hasil belajar siswa yang rendah karena jenuh didalam kelas. Hasil penelitian menunjukkan adanya peningkatan keaktifan (proses pembelajaran) dan hasil belajar mengindikasikan bahwa kualitas pembelajaran sejarah Indonesia di kelas XI IPS OL meningkat menjadi semakin baik.

\section{SIMPULAN}

Berdasarkan hasil penelitian diatas menunjukkan bahwa keaktifan dan hasil belajar siswa mengalami peningkatan dari pra siklus hingga siklus II. Proses (keaktifan) dan hasil belajar yang baik ini menunjukkan bahwa kualitas pembelajaran sejarah di kelas XI IPS OL meningkat. Peningkatan yang terjadi menunjukkan sebuah peningkatan yang cukup baik, bahkan setelah siklus I sudah menunjukkan adanya sebuah peningkatan. Meningkatnya kualitas pembelajaran di kelas XI IPS OL menunjukkan bahwa penerapan outdoor learning berbasis inkuiri berhasil menyelesaikan masalah yang dihadapi.

\section{Saran}

Berdasarkan kesimpulan disatas saran yang dirumuskan adalah memberikan himbauan kepada guru masing-masing mata pelajaran untuk menciptakan pembelajaran yang menyenangkan. Guru mata pelajaran sejarah hendaknya terus berinovasi untuk menciptakan pembelajaran yang menyenangkan bagi siswa. Siswa hendaknya terus belajar, memperhatikan guru, dan bersikap aktif selama mengikuti pembelajaran. Peneliti selanjutnya dapat meneliti penerapan outdoor learning berbasis inkuiri dengan jenis pendekatan yang lain.

\section{DAFTAR PUSTAKA}

Arifin, Z. 2013. Evaluasi Pembelajaran; Prinsip, Teknik, Prosedur. Bandung: PT. Remaja Rosdakarya.

Rusman, Kurniawan, D. dan Riyana, C. 2012. Pembelajaran Berbasis Teknologi Informasi dan Komunikasi; Mengembangkan Profesionalitas Guru. Jakarta: Rajawali Press.

Sanjaya, W. 2011. Perencanaan dan Desain Sistem Pembelajaran. Jakarta: Kecana Prenada Media Group.

Sudjana, N. 2011. Penilaian Hasil Proses Belajar Mengajar. Bandung: PT. Remaja Rosdakarya.

Suprihatiningrum, J. 2014. Strategi Pembelajaran; Teori dan Aplikasi. Yogyakarta: Ar-Ruzz Media.

Suyono dan Hariyanto. 2011. Belajar Pembelajaran; Teori dan Konsep Dasar. Bandung: PT. Remaja Rosdakarya Offset.

Wati. 2013. Efektifitas Pendekatan Content and Language Integrated Learning (CLIL) Melalui Running Dictation untuk Meningkatkan Hasil Belajar dan Keterampilan Berkomunikasi Lisan Sekolah Bilingual. Skripsi tidak diterbitkan. Semarang: FMIPA Universitas Negeri Semarang. (Online). (unnes.ac.id), diakses tanggal 28 April 2016. 


\section{KETENTUAN PENULISAN ARTIKEL JURNAL KALPATARU}

1. Naskah berbahasa Indonesia yang disempurnakan bertemakan kesejarah yang meliputi hasil penelitian sejarah, pengajaran sejarah dan penelitian kebudayaan.

2. Naskah harus asli dan belum pernah dimuat dalam media lain. Naskah dapat berupa hasil penelitian/artikel kajian konseptual yang ditulis oleh perorangan dan atau kelompok.

3. Naskah ditulis dengan cara-cara yang sesuai dengan ketentuan penulisan artikel ilmiah menggunakan bahasa Indonesia yang baku, berupa ketikan, beserta soft file dalam CD-RW atau dengan mengirimkan email pada redaksi jurnal Kalpataru dengan alamat jurnalkalpatarusejarah@gmail.com, spasi tunggal, jenis huruf arial narrow ukuran 12, dengan panjang naskah antara 8-15 halaman pada kertas A4.

4. Artikel hasil penelitian memuat:

JUDUL

Nama Penulis

Abstrak

\section{A. PENDAHULUAN}

B. METODE PENELITIAN

C. HASIL DAN PEMBAHASAN

D. SIMPULAN

DAFTAR PUSTAKA
: XXX (HURUF KAPITAL)

: (disertai jabatan, institusi, dan email)

: (Bahasa Indonesia yang memuat 100-200 kata diikuti kata kunci, dengan jenis huruf arrial narrow dan ukuran huruf 11 serta dicetak miring).

: (memuat latar belakang masalah, tinjauan pustaka secara ringkas, masalah penelitian, dan tujuan penelitian).

: (berisi simpulan).

: (berisi pustaka yang dirujuk dalam uraian naskah).

5. Artikel Kajian Konseptual memuat:

\section{JUDUL \\ Nama Penulis \\ Abstrak \\ PENDAHULUAN \\ Sub Judul \\ Simpulan \\ DAFTAR PUSTAKA}

: XXX (HURUF KAPITAL)

: (disertai jabatan, institusi, dan email)

: (Bahasa Indonesia yang memuat 100-200 kata diikuti kata kunci, dengan jenis huruf arrial narrow dan ukuran huruf 11 serta dicetak miring.

: (memuat latar belakang masalah, tinjauan pustaka secara ringkas, masalah penelitian, dan tujuan penelitian).

: Sesuai dengan kebutuhan (tanpa numbering).

: (berisi simpulan dan saran).

6. Referensi sumber dalam teks artikel ditulis dengan menggunakan side note, contoh (Jalaludin, 1991:79); sementara penulisan daftar pustaka disusun dengan ketentuan. Nama pengarang. Tahun terbit. Judul (dicetak miring). Kota terbit: Nama Penerbit. Contoh: Koentjaraningrat. 2010. Manusia dan Kebudayaan di Indonesia. Jakarta: Djambatan. Daftar pustaka hanya memuat pustaka/sumber yang dirujuk dalam uraian dan disusun menurut abjad tanpa nomor urut.

7. Naskah yang dimuat akan disunting kembali oleh redaksi tanpa mengubah isinya.

8. Naskah yang ditolak (tidak bisa dimuat) akan dikirim kembali ke penulis dengan pemberitahuan tertulis dari redaksi atau melalui email.

9. Penulis yang naskahnya dimuat akan mendapat 1 (satu) majalah nomor yang bersangkutan.

10. Kontak person: Muhamad Idris (081271498618); Eva Dina Chairunisa (082281267851); Jeki Sepriady (085269261780). 